\title{
Liberalismo e humanismo as linguagens da consciência cívica na Inglaterra do século XVII*
}

\section{Liberalism and humanism \\ the languages of the civic conscience in 17th century England ${ }^{\star *}$}

\author{
JAVIER AMADEO \\ Professor do Departamento de Ciências Sociais \\ Universidade Federal de São Paulo (UNIFESP) - Campus Guarulhos \\ Estrada do Caminho Velho, 333. Bairro dos Pimentas \\ CEP 07252-312 - Guarulhos - SP \\ javier.amadeo@unifesp.br
}

RESUMO O surgimento da consciência cívica na Inglaterra do século XVII esteve vinculado à controvérsia constitucional nas décadas que precederam a guerra civil. 0 conflito político provocou uma intensa exploração intelectual, dando lugar ao surgimento de ideias e conceitos que se transformariam em dominantes no discurso e no pensamento políticos modernos. 0 texto tem como foco a análise dessas linguagens que contribuíram para o desenvolvimento dessa consciência cívica. Analisaremos, portanto, a linguagem do direito e os elementos nesta linguagem que contribuíram para o desenvolvimento da consciência cívica moderna. Se for verdade que a linguagem do direito foi um dos principais legados políticos do século XVII,

* Artigo recebido em: 28/10/2010. Aprovado em: 19/12/2011.

** O presente artigo é resultado de um projeto de pós-doutorado, em desenvolvimento, no Departamento de História da Universidade de São Paulo, sob supervisão do Professor Modesto Florenzano; o mesmo contou como o apoio financeiro da FAPESP. Gostaria de agradecer ao Professor Florenzano pela revisão paciente e pelos valiosos comentários, no entanto assumindo que qualquer erro ou emissão é de minha exclusiva responsabilidade. 
o texto sugere que a linguagem da virtude também teve uma importância decisiva e analisa a existência de uma articulação complexa e contraditória entre ambas no surgimento da moderna consciência cívica.

Palavras-chave história do pensamento político moderno, liberalismo, humanismo

ABSTRACT The emergence of civic consciousness in 17th century England was linked to constitutional controversy in the decades preceding the civil war. The political conflict sparked an intense intellectual exploration, giving rise to the emergence of ideas and concepts that became dominant in modern political thought. The text focuses on the analysis of these languages that contributed to the development of civic consciousness. We will analyze, therefore, the language of law and the elements that contributed to the development of modern civic consciousness. If it is true that the language of law was one of the main political legacies of the 17th century, the text suggests that the language of virtue also had a crucial importance and we discuss the existence of a complex and contradictory articulation between both in the emergence of modern civic consciousness.

Keywords history of modern political thought, liberalism, humanism

\section{Introdução}

O pensamento político das primeiras décadas do século XVII esteve centrado em uma questão conflitiva: a relação entre a prerrogativa régia e a common law. Esta era uma forma mais ampla do contraste entre law e equity que caracterizou o período Tudor. Durante as primeiras duas décadas do século XVII, as consequências da disputa entre ambos os princípios básicos de legitimidade política, esteve dissimulada pelo particularismo dos conflitos concretos. Na realidade esses princípios representavam ideias diferentes, e incompatíveis entre si, sobre organização e legitimidade. Neste sentido, a existência do direito consuetudinário e da prerrogativa era a forma que o princípio de dupla majestade adquiriu no século XVII. 0 contraste entre law e equity se ampliou até tornarem-se mutuamente excludentes, equity gradualmente ficou confinada à justiça, independente da common law, administrada pelo Conselho Privado (Privy Council). Chancelaria (Chancery), a Câmara Estrelada (Star Chamber) e o Tribunal de 
Recursos (Court of Requests). A oposição às reivindicações jurisdicionais das Cortes de Prerrogativa argumentava que a common law tinha jurisdição sobre todos os assuntos; o resultado foi uma série de disputas jurisdicionais e no fim um desacordo legal insuperável. ${ }^{1}$

A disputa entre estes princípios de legitimidade teria uma enorme importância no surgimento da consciência cívica. A erupção das hostilidades armadas entre o Rei e o Parlamento em 1642 provocou a ruptura da ordem política inglesa, e quando a monarquia foi restabelecida em 1660, a Restauração foi realizada sobre fundamentos inteiramente diferentes. A partir da ruptura da ordem política e da assunção da soberania pelo Parlamento Longo, o debate e a discussão de ideias se liberaram de suas travas tradicionais. Como afirma Hanson, este grande debate foi a primeira expressão de uma consciência cívica articulada. Pela primeira vez desde a antiguidade clássica assistimos a uma discussão geral sobre a natureza e os propósitos da sociedade e do governo. A discussão envolvia uma exploração deliberada e autoconsciente de questões fundamentais como a relação dos homens enquanto concidadãos e, por sua vez, entre o corpo político, constituído pelos cidadãos, e os governantes. Foi o surgimento desta consciência da dimensão pública dos temas que separa a ordem política moderna da ordem política tradicional. No entanto, o ponto culminante desta discussão política não foi alcançado imediatamente, pois, inicialmente, a disputa entre Rei e Parlamento foi percebida e travada em termos legais e tradicionais. Foi somente no processo de radicalização política e nos debates dos anos imediatamente posteriores a 1642 que os participantes começaram a apreciar a natureza fundamental das diferenças. O Parlamento, gradativamente, esvaziou a autoridade tradicional do Rei e assim abriu caminho para os debates que eventualmente produziram preocupações difundidas e autoconscientes sobre o problema de um novo arranjo constitucional. ${ }^{2}$

O surgimento da consciência cívica na história inglesa esteve vinculado à controvérsia constitucional nas décadas que precederam a guerra civil. 0 elemento central foi uma reestruturação da visão política no meio de uma crise intensa, e o que emergiu deste prolongada disputa foi um sentido radicalmente novo dos direitos e deveres do cidadão. O conflito político provocou uma intensa exploração intelectual, dando lugar ao surgimento

\footnotetext{
1 HANSON, Donald W. From kingdom to commonwealth. Cambridge, Mass.: Harvard University Press, 1970, p.281.

2 HANSON, Donald W. From kingdom to commonwealth, p.309-311.
} 
de ideias e conceitos que se transformariam em dominantes no discurso e no pensamento políticos modernos. ${ }^{3}$

A Inglaterra do período podia ser definida como um corpo místico, isto é, como uma comunidade de razão apta para reconhecer as leis racionais e uma comunidade de experiência adequada para seguir um conjunto de costumes transmitidos pela tradição. Um desafio central para analisar o período é entender como surgiu uma consciência de característica cívica em um ambiente intelectual dominado por conceitos e teológicos jurídicos. ${ }^{4}$

Com o colapso da autoridade política e guerra civil elementos diferentes de tradições discursivas distintas puderam se desenvolver, dando lugar ao surgimento da consciência cívica. Como sustenta Pocock, a dissolução de facto do governo neste processo foi central porque colocou a necessidade de pensar a forma de governo que devia substituí-la, colocando uma série de problemas políticos, éticos e legais em relação às obrigações do súdito e em relação ao direito do governo de exigir obediência. Neste momento de conflito político intenso, e em meio a um quadro conceitual contraditório, diferentes doutrinas tentaram refletir, nas linguagens da lei - civil e natural -, e do humanismo sobre uma série de problemas teóricos em relação a: direito, propriedade, revolução, e a relação entre autoridade política e obrigação. ${ }^{5}$

0 texto tem como foco a análise dessas linguagens que contribuíram para o desenvolvimento da consciência cívica. Analisaremos, portanto, a linguagem do direito - do direito natural e do direito civil - e os elementos nesta linguagem que contribuíram para o desenvolvimento da consciência cívica moderna. Se for verdade que a linguagem do direito foi um dos principais legados

3 Alguns trabalhos fundamentais, entre a ampla bibliografia sobre o tema, são: ASHCRAFT, Richard. Revolutionary politics \& Locke's two treatises of government. Princeton/NJ: Princeton University Press, 1986; BURNS, J. H. (ed.). The Cambridge history of political thought 1450-1700. Cambridge: Cambridge University Press, 2004; DUNN, John. Political obligation in its historical context. Cambridge: Cambridge University Press, 2002; HANSON, Donald W. From kingdom to commonwealth; HILL, Christopher. O mundo de ponta cabeça. São Paulo: Companhia das Letras, 2001 (1972); LASLETT, Peter. Introdução. In: LOCKE, John. Dois tratados sobre o governo. São Paulo: Martins Fontes, 2001; POCOCK, J. G. A. The ancient constitution and the feudal law. Cambridge: Cambridge University Press, 1987 (1957); POCOCK, J. G. A. The maquiavellian moment: Florentine political thought and the Atlantic Republican tradition. Princeton/Oxford: Princeton University Press, 1975; POCOCK, J. G. A. Linguagens do ideário político. São Paulo: EDUSP, 2003. POCOCK, J. G. A. Virtudes, direitos e maneiras: um modelo para historiadores do pensamento político. In: Linguagens do ideário político; SKINNER, Quentin Vision of politics. Hobbes and Civil Science, v.III. Cambridge: Cambridge University Press, 2002; SKINNER, Quentin. Los fundamentos del pensamiento político moderno. México: Fondo de Cultura Económica, 1993 (1978); WOODHOUSE, A. S. P. Puritanism and liberty. Chicago: J. M. Dent \& Son Ltd London, 1974.

4 POCOCK, J. G. A. The maquiavellian moment.

5 POCOCK, J. G. A. Introduction, In: HARRINGTON, J. The commonwealth of Oceana. Cambridge: Cambridge University Press, 1996. 
políticos do século XVII, o texto sugere que a linguagem da virtude também teve uma importância decisiva e a existência de uma articulação complexa e contraditória entre ambas no surgimento da moderna consciência cívica.

\section{Common Law: direitos e obrigações}

A linguagem fundamental a partir da qual se articulou a consciência cívica na Inglaterra do período foi a linguagem da lei, tanto da lei natural como da lei civil. A linguagem da lei, e os conceitos centrais construídos em torno dela, como direitos, liberdade, cidadania, soberania, etc., seriam alguns dos legados mais importantes do discurso político do século XVII.

Uma das características centrais da apresentação jurídica da liberdade era a distinção entre libertas e imperium, liberdade e autoridade, indivíduo e soberania, privado e público, estabelecendo uma série de dicotomias e de formas de se expressar sobre o domínio da política que se transformariam em dominantes no pensamento político moderno. ${ }^{6}$

A visão predominante da política e da sociedade na Inglaterra de meados do século XVII era uma visão conservadora e legalista, e as disputas teóricas e políticas giravam entorno das ideias de lei e costume. A lei também consagrava os direitos, privilégios, liberdades e propriedades dos indivíduos. Governantes e governados tinham propriedade que desfrutavam com base na lei. No âmbito da monarquia territorial e jurisdicional o indivíduo, tomado do ponto de vista positivo era possuidor de direitos, fundamentalmente dos direitos à terra e à justiça, que afetavam esta posse; e a estrutura de autoridade ascendente existia basicamente como uma estrutura de costume, jurisdição e liberdade, na qual esses direitos eram incorporados, preservados e encontravam-se com uma estrutura descende de autoridade que existia para assegurar sua continuidade. ${ }^{7}$ Este era o mundo que operava a partir das noções de jurisdictio e de gubernalucum, neste universo o sujeito possuía propriedade e direitos proprietas que possuía em razão da lei - e estava subordinado a um princípio de autoridade que não tinha origem nos seus direitos, e sim em um princípio de autoridade descendente que partia de Deus. Um dos problemas centrais do debate político do século XVII era até que ponto estes dois esquemas conceituais jurisdictio e gubernalucum - poderes ascendentes e descentes, direitos e deveres - estavam integrados e, como consequência que sucedia, em termos de obrigação política, quando a sua não integração tornava-se evidente. ${ }^{8}$

6 POCOCK, J. G. A. Virtudes, direitos e maneiras, p.86-87.

7 POCOCK, J. G. A. The maquiavellian moment.

8 Sobre o funcionamento deste esquema conceitual, ver a obra seminal de MCILWAIN, Charles Howard. Constitutionalism: ancient and modern. Indianapolis: Liberty Fund Inc., 2008 (1958); e também a obra de 
Portanto, para entender o desenvolvimento da consciência cívica é essencial analisar o funcionamento desta estrutura de direitos e deveres contida basicamente na estrutura da common law.

Como chave para seu passado os ingleses conheciam apenas um sistema de direito. Para eles era possível acreditar que, tão distante retrospectivamente como sua história se estendia, o direito comum das Cortes do Rei era o único direito que tinha se desenvolvido e vigorado dentro do reino; para os registros e narrativas da Inglaterra nenhum outro direito havia contido uma importância comparável. A common law [direito consuetudinário] era o único direito pelo qual a terra podia ser ocupada e os crimes punidos, e fundamentalmente determinava os direitos e obrigações seculares dos homens. 0 pensamento político do período estava caracterizado pela presença e natureza desta instituição inglesa única; a interpretação que os ingleses do período faziam de sua história constitucional, legal e política estava de acordo com aquela feita pelas escolas jurídicas da common law. ${ }^{9}$

Um dos aportes fundamentais da obra de J. G. A. Pocock - The Ancient Constitution and Feudal Law - foi ter reconhecido a doutrina da ancient constitution como um componente distintivo do pensamento político do período Stuart; mostrando o papel da perspectiva da common law para dar forma a esta doutrina. "Acreditar na antiguidade da common law incentivou a crença na existência da ancient constitution, com referência a qual eram elaborados constantemente precedentes, máximas e princípios que eram constantemente declarados, e os quais se afirmavam como imunes frente às prerrogativas do rei". ${ }^{10}$ A fonte desta doutrina era Sir Edward Coke, cujo Reports (1600-15), e Institutions of the Laws of England (1628-1644) continham as ideias históricas e legais vinculando a ancient constitution com a common law. ${ }^{11}$

Sir Edward Coke definia o direito da Inglaterra como sendo de dois tipos: common law [direito consuetudinário] e statutory law [direito estatutário]. O primeiro descrito comumente como direito não escrito, o segundo como direito escrito. Este último era produto do processo legislativo do Parlamento, conformado pelo Rei e pelas duas Câmaras, o qual podia elaborar novas leis, ou alterar, as antigas. A common law era geralmente definida em termos de costume ancestral e descrita como direito tradicional ou costumeiro com raízes medievais profundas; não existia um legislador identificável, ela era declarada pelos juízes reais nas Cortes da common law, e sua antiguidade,

POCOCK, J. G. A. The maquiavellian moment; e HANSON, Donald W. From kingdom to commonwealth.

9 POCOCK, J. G. A. The ancient constitution and the feudal law, p.30-31.

10 POCOCK, J. G. A. The ancient constitution and the feudal law, p.46.

11 Ver também WESTON, Corinne Comstock. English Constitutional theory and the house of lords, 1556-1832. Londres: Routledge \& Kegan Paul, 1965; e WESTON, Corinne Comstock e GREENBERG, Janelle Renfrow. Subjects and sovereigns. Cambridge: Cambridge University Press, 1981. 
imemorial, ficava estabelecida quando declarada. Ambas as concepções de direito influenciaram profundamente o pensamento político do período, e o conflito entre ambas foi central na discussão política. ${ }^{12}$

Como afirma Pocock, a doutrina da ancient constitution não era uma reivindicação de legitimidade prescritiva através da antiguidade imemorial do costume, tampouco um meio de sustentar a supremacia legislativa do Parlamento, ou da Câmara dos Comuns, atuando de forma isolada; o elemento central da doutrina da ancient constitution era a afirmação de que a common law, em razão da sua antiguidade, era a lex terrae [direito da terra] que protegia a propriedade e a liberdade dos súditos, e por meio de sua legalidade a autoridade régia estava limitada para proceder em temas relacionados com a propriedade e com a liberdade. A antiguidade da common law estabelecia seu elemento fundamental no sentido de que nenhuma outra lei obtida como parte da autoridade régia podia ter precedência. O Parlamento, como era reivindicado comumente pela Câmara dos Comuns, era tão antigo como a common law - isto era afirmado pelas mesmas estratégias de apelo ao precedente estabelecido pela antiguidade da lei -, e dado que o Parlamento era a instituição que elaborava os estatutos, mediante os quais a lei era alterada, era ele quem estava especialmente credenciado para manter ou alterar a common law. ${ }^{13}$

Os debates parlamentares e as distintas controvérsias políticas envolvendo direito e constituição eram invariavelmente travados em termos de um apelo ao passado; e advogados da common law e antiquários eram respeitados como autoridades importantes em matéria política. A maioria dos pensadores que contribuíram de alguma forma ao desenvolvimento da teoria política do século XVII, entre eles Hobbes, Hunton, Filmer, Parker, Selden, Sidney e Harrington, dedicaram parte de suas páginas a discutir a antiguidade da constituição. ${ }^{14}$

Para Pocock, é possível construir uma história das formas em que o pensamento histórico foi usado como argumento político e um estudo das formas em que teoria política e história estavam relacionadas nas mentes dos homens que escreviam e pensavam em ambos os modos. ${ }^{15}$ Para o inglês típico de seu tempo, parecia apropriado acreditar que a característica essencial de sua constituição era a antiguidade, o fundamento no passado remoto era essencial para estabelecê-la de forma segura no presente. O pensamento histórico fundamentado nesta crença ajudou a modelar as mentes do período e, portanto,

12 WESTON, Corinne Comstock. English Constitutional theory and the house of lords, 1556-1832, p.375-376.

13 POCOCK, J. G. A. The ancient constitution and the feudal law, p.302.

14 O texto de Hobbes Diálogo entre um filósofo e um jurista é um bom exemplo da importância política da common law, inclusive para autores que não argumentavam nesses termos. Nesta obra Hobbes realiza um exame do papel da common law no sistema jurídico inglês como defendida por Sir Edward Coke.

15 POCOCK, J. G. A. The ancient constitution and the feudal law. 
conhecer seu funcionamento é de vital importância para entendê-la. A partir de um pensamento histórico deste tipo o Parlamento e as Cortes da common law podiam reivindicar direitos e privilégios baseados na sua existência em tempos remotos, mesmo quando estes fossem de tipo novo. 0 tipo de raciocínio da "mente da common law" possibilitava que, a partir de fontes legais, se produzissem evidências de ações realizadas em um passado distante, que poderiam ser identificadas com condições contemporâneas e reivindicadas como precedentes. Reivindicar a existência de um precedente implicava alegar que o sistema de leis, tão antigo como o precedente, ainda estava vigente e este tipo de argumento sugeria o princípio de que o sistema legal da Inglaterra era prévio à Conquista Normanda. ${ }^{16}$

Os juristas da common law começaram a reescrever a história da Inglaterra em linhas parlamentares durante a afirmação da Câmara dos Comuns no reinado de Elizabeth, e no começo do século XVII os Comuns já tinham insistido que o corpo inteiro de seus privilégios devia ser reconhecido como próprios por direito de tempo imemorial. A busca de precedentes resultou no processo de construção de um corpo de direitos e privilégios declarados como supostamente imemoriais, e isto, junto com a crença de que a Inglaterra era governada pela força do direito, resultou, por sua vez, no conceito mais importante e elusivo do século XVII, a ideia de direito fundamental (fundamental law). O direito fundamental era o direito ou constituição antiga; o conceito tinha sido construído pela procura de precedentes junto com o hábito das mentes da common law que presumiram que qualquer coisa que estivesse na common law era imemorial. O conteúdo do conceito variava de tempos em tempos, e no momento em que o Parlamento passou a reivindicar novos poderes, estes foram representados como imemoriais e incluídos na lei fundamental. À medida que o século XVII progredia afirmações sobre o direito como imemorial foram substituídas por afirmações sobre o Parlamento, e especialmente a Câmara dos Comuns, de que este era imemorial. Um dos temas centrais da história do pensamento político do século XVII é o percurso desde a reivindicação da existência da ancient constitution, com o Parlamento como guardião, até a reivindicação do Parlamento como autoridade soberana do reino. Este processo de transição entre uma reivindicação e outra foi um processo complexo, e ainda não esta claro quando e como se produziu, porém parece existir um acordo entre os estudiosos de que este tem sido em grande medida incompleto. ${ }^{17}$

16 Sobre a importância da Conquista Normanda como argumento político ver: HILL, Christopher. Puritanism and revolution: studies in interpretation of the English Revolution of the 17th century. New York: St. Martin's Press, 1997.

17 POCOCK, J. G. A. The ancient constitution and the feudal law, p.46-49. 
A ideia da common law como imemorial, não implica afirmar que ela fosse estática ou imutável. Como afirma Pocock, um jurista como Sir Edward Coke podia considerar a conservação de um costume antigo como prova de que tinha sobrevivido ao teste do tempo e dado evidência de sua modernidade. A noção de costume e de uso é ambígua, ela implica tanto conservação como adaptação. 0 conteúdo da lei era menos importante que o próprio processo jurídico - uso, juízo e estatuto - que era imemorial. A reforma de leis obsoletas e a elaboração de novas era perfeitamente compatível com a visão da common law como fundamentada no uso antigo; a noção de reforma e refinamento era inerente às formas de pensar da common law. Noções como costume comum do reino e tempo e razão, utilizadas por advogados da common law, faziam possível ver costume e razão, julgamento e estatuto, como existindo em uma simbiose, e o apelo ao tempo imemorial não era de fato compulsivo, mas disponível quando seu uso fosse inevitável. Em suma, o argumento central de Pocock pode ser resumido assim: por um lado, o discurso político dos ingleses foi por um longo tempo conduzido por mentes treinadas na common law; e por outro, que essas mentes foram treinadas por longo tempo para proceder de acordo com certos pressupostos, e seguir certos padrões de argumentação, caracterizados pela crença na ancient constitution. ${ }^{18}$

Desta forma, o raciocino de tipo histórico era utilizado fundamentalmente como um argumento político. Mais importante ainda, do que o próprio conteúdo da common law, era a forma de raciocínio que ela possibilitava; e que permitia que fosse utilizada essencialmente como uma forma de alegação política.

A Petição de Direitos (Petition of Rights), de 1628, marca o ponto no qual a doutrina da ancient constitution tinha alcançado uma preponderância inquestionável, mas ao mesmo tempo havia sido incapaz de definir a prerrogativa em termos diferentes de absolutos. As posições do Parlamento, e especialmente da Câmara dos Comuns, tinham contribuído para definir a existência de um espaço de atuação próprio para a prerrogativa régia, entretanto a common law devia determinar os mecanismos e os limites da sua ação.

Se de uma parte a doutrina da ancient constitution alcança seu momento de consolidação, do mesmo modo parece continuar existindo uma dualidade básica no fundamento da autoridade; duas doutrinas da autoridade política que apresentam fundamentos diferentes e sem conexão entre elas. Este problema em relação à autoridade pode ser relacionado com a tradição de pensamento associada com Fortescue que distinguia entre governo regale e politicum, mas esta tradição era diferente da doutrina do governo misto porque os poderes não se combinavam. Este conflito teórico pode ser colocado como

18 POCOCK, J. G. A. The ancient constitution and the feudal law, p.274-276. 
um dos impasses políticos que influenciaram a eclosão da guerra civil, mas ao mesmo tempo serviu como ponto de partida para a evolução das linguagens políticas do período. ${ }^{19}$

As circunstâncias políticas do período da guerra civil ofereceram a oportunidade para uma importante revisão da doutrina da ancient constitution. Esta revisão, que levou à teoria da soberania mista e conjunta do Rei e do Parlamento, poderia ter sido elaborada pelos partidários do Parlamento com base aos argumentos que temos exposto até aqui, no entanto este processo de mudança conceitual chave para a época foi levado adiante com resultados ambíguos pelos partidários do próprio Rei como forma de defender suas prerrogativas.

His Majesty's Answer to the Nineteen Propositions of Parliament junho de 1642 - tem sido considerado um dos documentos cardinais do pensamento político inglês, em grande medida graças ao trabalho de Corinne Weston. ${ }^{20}$ Nesta declaração fundamental, o Rei modifica a posição anterior da monarquia, quando descreve: "a antiga, adequada, feliz, bem equilibrada e nunca suficientemente elogiada constituição do governo do reino". A fonte humana da ancient constitution não era o Rei, mas a antiga experiência dos ingleses. Outro elemento fundamental do documento se refere às características do governo inglês; ele afirmava que existiam três formas de governo entre os homens - monarquia absoluta, aristocracia e democracia - cada uma delas com vantagens e desvantagens, a experiência e sabedoria dos ancestrais tinha produzido uma mistura para dar ao reino os benefícios das três, sem seus inconvenientes. 0 equilíbrio (balance) residia na combinação das formas de governo representadas nos três estados do reino, Rei, Lordes e Comuns. O poder de elaboração das leis, que passou a ser o elemento central da soberania, residia nos três conjuntamente; ao Rei se conferia a prerrogativa, à Câmara dos Lordes o poder de tribunal de justiça, e à Câmara dos Comuns o direito de aceitar novos tributos. 0 documento concluía com uma advertência aos Comuns contra qualquer demanda de maiores atribuições, as quais poderiam destruir todos os direitos e propriedades, todas as distinções e méritos. ${ }^{21}$ His Majesty’s Answer é um

19 HANSON, Donald W. From kingdom to commonwealth, analisando as condições nas quais a consciência cívica surgiu na Inglaterra, conclui que o esquema conceitual de jurisdictio e gubernalucum nunca esteve totalmente integrado, o problema deste esquema residia na própria concepção da autoridade política. Em essência a idéia era que a autoridade legítima residia tanto no Rei como no Parlamento, de forma independente; esta era a característica básica da noção de "dupla majestade". Desta forma o colapso de tal dualidade durante a guerra civil inglesa teria sido a condição básica para o surgimento da consciência cívica.

20 WESTON, Corinne Comstock. English Constitutional theory and the house of lords, 1556-1832.

21 Cf. His Majesty's Answer to the Nineteen Propositions of Both Houses of Parliament, In: KENYON, J. P. (ed.). The Stuart Constitution, 1603-1688: documents and commentary. Cambridge: Cambridge University Press, 1986. 
documento rico e polêmico e é possível realizar diversas interpretações sobre sua importância política.

0 trabalho de Corinne Weston ${ }^{22}$ concentrou-se nas implicações do poder legislativo conjunto, como elemento central da soberania. Para a autora, nesta conjuntura a common law se tornou subordinada à moderna teoria de soberania parlamentar, seu principal papel era afirmar que a soberania parlamentar, na qual Rei, Lordes e Comuns elaboravam a lei como três estados coordenados, havia existido em princípios constantes desde tempos imemoriais. A despeito de parecer paradoxal o antigo constitucionalismo combinava a partir deste momento a forma de raciocinar e a linguagem da common law com a defesa da moderna teoria da soberania parlamentar. No momento em que o debate se centrou nos problemas do poder, a discussão política entrou em um território novo: com dois temas que passariam a ser centrais, o direito prescritivo dos Comuns à representação no Parlamento e à natureza do processo de elaboração legislativa. ${ }^{23}$

Para Pocock, por sua vez, este documento marca um momento chave na história do pensamento político inglês, no qual a ancient constitution passa a ser identificada positivamente com a constituição mista. Esta ideia de governo misto implicava uma ideia de combinação de elementos políticos que tinham até esse momento sido colocados como polaridades: prerrogativa com liberdade, regale com politicum, e pacto ou costume, que limitava o Rei a observar as formas de procedimento parlamentares, com common law. A teoria polibiana do governo misto, na qual o Rei era um dos três componentes do poder ou dos três estados juntos na soberania legislativa, talvez pudesse implicar algumas coisas além das intenções dos autores; um governo misto deste tipo não podia ser justificado simplesmente por um apelo ao costume imemorial, ou imaginado como havendo passado a existir meramente por meio de operações de razão e uso, ou costume e estatuto. Ele havia sido estabelecido, afirmava o texto, pela "sabedoria", operando de acordo com a "prudência" em uma situação inerentemente problemática; e o tipo de solução oferecido parecia mais com um tipo de ato legislativo que com um recurso ao costume. ${ }^{24}$

A re-elaboração da doutrina da ancient constitution realizada em Answer to the Nineteen Propositions proporcionou a possibilidade de entender o governo inglês como "equilibrado", mas, ao mesmo tempo, colocou de uma maneira involuntária o problema de o que fazer quando esse equilíbrio fosse destruído. $\mathrm{O}$ apelo à doutrina do governo equilibrado colocava ao mesmo tem-

22 Ver também, WESTON, Corinne Comstock e GREENBERG, Janelle Renfrow. Subjects and sovereigns.

23 WESTON, Corinne Comstock. English Constitutional theory and the house of lords.

24 POCOCK, J. G. A. The ancient constitution and the feudal law, p.310-311. 
po o dilema da espada. Este dilema foi incessantemente debatido na chamada Engagement Controversy ou controvérsia de facto. ${ }^{25}$

A execução do Rei e a proclamação da Commonwealth colocaram a necessidade de persuadir os grupos moderados e os radicais de que a revolução tinha acabado; apresentando razões convincentes para obedecer e se submeter ao novo governo, em lugar de continuar com a luta. Era necessária uma teoria da obrigação política em termos que permitissem legitimar o novo poder, satisfazendo duas condições contrastantes. Por um lado, esta teoria devia ter uma forma suficientemente familiar para ser aceita por presbiterianos e inclusive pela opinião monárquica. Por outro, devia ser capaz de executar a tarefa revolucionária de justificar a obrigação de obedecer a um poder político meramente de facto. Esta controvérsia colocou em pauta o debate de que obrigava a consciência a obedecer quando os poderes eram exercidos de facto e não de jure. Em uma circunstância como esta não fazia sentido debater a antiguidade do governo, já que este era uma discussão sobre o que era de jure. Um governo sem legitimidade legal colocava uma série de problemas que dificilmente podiam ser resolvidos no esquema conceitual colocado pela ancient constitution; era necessário um tipo de reflexão que enfatizasse o problema da espada, o problema da autoridade de facto, desta forma fez-se necessário o desenvolvimento de novos discursos sobre a autoridade política para preencher as lacunas colocadas pela nova situação política.

Os teóricos mais radicais do poder de facto viram-se em um estado de anarquia - que Harrington mais tarde chamaria de condição de "dor e miséria" - e procuraram um caminho de saída. Estes autores do "estado de natureza" indagaram o que existia na natureza do indivíduo que o obrigava a obedecer ao governo, mesmo quando ele fosse o elemento central na constituição da autoridade política. Os mais miseráveis dos seres vinculados por servidão e obediência ao déspota para a preservação de seus direitos de existência, era não obstante o constituinte do governo, o legislador do mundo natural. Um das hipóteses levantadas por Pocock é que o mundo de "dor e miséria" que se seguiu ao colapso da ancient constitution serviu como um dos elementos decisivos do individualismo radical das teorias do direito natural, que foi sem dúvida um dos logros mais transcendentes da teoria política do século XVII. ${ }^{26}$

A ideologia da ancient constitution afirmava que a common law, em razão da sua antiguidade, era a lei que protegia a propriedade e a liberdade dos súbditos, e limitava a autoridade do rei em temas relacionados com a

25 Entre a ampla literatura ver SKINNER, Quentin. Conquest and consent: Thomas Hobbes and the engagement controversy. In: AYLMER, G. E. (ed.). The interregnum: the quest for settlement 1646-1660. Londres: Macmillan, 1972; SKINNER, Quentin. Vision of politics.

26 POCOCK, J. G. A. The ancient constitution and the feudal law, p.324. 
propriedade e com a liberdade; propriedade, estrutura social e governo existiam como definidas pelo direito. Como afirma Pocock, é possível caracterizar a ideologia da ancient constitution como um modo de consciência cívica particularmente apropriada para a gentry se afirmando no Parlamento, nos tribunais e na administração local da common law. 0 súdito percebia o reino como uma estrutura de costumes, e ao rei, juízes, e conselheiros, como engajados em uma atividade política permanente de preservar e transmitir os usos e costumes que faziam da Inglaterra o que era. Portanto, a ideologia da ancient constitution funcionava como uma forma de consciência cívica já que definia, ainda que em termos tradicionais, um reino público e um modo de ação política. ${ }^{27}$

\section{Liberdade e propriedade na linguagem do direito natural}

Outra das linguagens fundamentais na qual se expressaram as controvérsias políticas do período foi a linguagem da lei natural, ou do direito natural. A despeito da falta de estudos que expliquem a relação no desenvolvimento de ambas, é possível afirmar que tanto a linguagem da lei civil como da lei natural foram essenciais para o surgimento da moderna consciência cívica. Uma das características particulares da linguagem dos direitos foi ter construído uma versão jurídica da liberdade, associando liberdade e direito (ius). Porém, esta linguagem tem um caráter ambíguo, e existem várias hipóteses sobre suas origens linguísticas e teóricas. ${ }^{28}$

Richard Tuck sustenta que o conceito de direitos emergiu no século XIII como resultado da assimilação de ius e dominium pelos Glosadores, particularmente Accursius e seus seguidores. De acordo com Tuck, "por volta do século XIV é possível afirmar que ter um direito é ser senhor ou dominus de um mundo moral relevante, para possuir dominium, isto é propriedade". ${ }^{29}$ Assim, um dos elementos centrais desta linguagem do direito natural é a relação entre os conceitos de dominium e ius, duas palavras que podem ser traduzidas como "propriedade" e "direito".

Um dos elementos centrais para o tema que nos ocupa, independente da controvérsia sobre as origens, é o tipo de relação entre liberdade e autoridade

27 POCOCK, J. G. A. The maquiavellian moment, p.341.

28 Sobre este ponto ver TUCK, Richard. Natural rights theories: their origin and development. Cambridge: Cambridge University Press, 1979; FINNIS, John. Natural law and natural rights. Oxford: Clarendon, 2005 (1980); BRETT, Annabel S. The development of the idea of citizen's rights. In: SKINNER, Quentin e STRÅTH, Bo. (eds.). States and citizens: history, theory, prospects. Cambridge: Cambridge University Press, 2003; DAGGER, Richard. Rights. In: BALL, T.; FARR, J. e HANSON, R. L. (eds.) Political innovation and conceptual change. Cambridge: Cambridge University Press, 1989.

29 TUCK, Richard. Natural rights theories, p.3. 
oferecida pela linguagem do direito natural. Por um lado, a definição de liberdade: a liberdade é definida pela lei, esta investe o cidadão de direitos. No entanto ao definir a liberdade do ponto de vista jurídico não investe o cidadão de nenhum papel no imperium, a linguagem da lei difere entre a libertas (liberdade), que dá garantia ao cidadão, e o imperium ou autoritas (autoridade) do magistrado que ministra a lei. ${ }^{30}$ Por outro lado, estabelece um tipo de relação especial entre cidadão e propriedade, a lei define o cidadão em termos de ius ad rem e do ius in re, que ele adquire por meio de seu papel na posse, transferência e administração das coisas. Desta forma, como afirma Pocock, o direito civil possibilita um individualismo possessivo em uma forma que antecede em muito o início do capitalismo e estabelece um tipo de relação particular entre autoridade e liberdade que os teóricos políticos chamam de liberalismo. ${ }^{31}$

A figura de Hugo Grotius foi chave no desenvolvimento das teorias do direito natural; o pensador holandês foi o artífice de uma nova "ciência da moralidade". Partindo de uma formação humanista e calvinista suas elaborações contribuíram para a transformação da cultura protestante e fizeram possíveis as teorias políticas dos séculos XVII e XVIII. Seu trabalho propunha uma teoria da justiça, que partia de pressupostos aristotélicos e de pensadores políticos protestantes, porém sua intenção era explicar as relações em termos de transferência de dominium, e desta forma sua teoria vai relacionar liberdade com propriedade de uma forma que não tinha sido feita antes.

Grotius combinou uma série de elementos das teorias humanistas e escolásticas. Para ele não existia propriedade no sentido estrito da palavra no estado de natureza: os escolásticos estavam errados ao pensar que existia um dominium natural igual ao dominium cívico, porém os humanistas se equivocavam ao negar aos homens qualquer direito no estado de natureza; existia um único tipo de direito, que podia ser qualificado de dominium por analogia. Para o pensador holandês o homem natural era sujeito de direitos, os direitos que possuía, apesar de não estritamente direitos de propriedade, eram categoricamente semelhantes. Este ponto ficava claro na argumentação de Grotius quando afirmava não haver necessidade de uma transição abrupta entre o estado natural e o civil, o que incluía as relações de propriedade familiar, baseada na ocupação. Assim, uma das características importantes da teoria de Grotius se relacionava com o princípio geral de ocupação; havia alguma coisa de natural no desenvolvimento da propriedade privada como resultado de um direito humano básico e inerente ao uso do mundo material, e nenhum acordo social era necessário para garantir este uso.

30 Uma formulação já clássica desta definição de liberdade negativa aparece no capítulo XXI do Leviatã de Hobbes ao analisar a liberdade dos súditos do reino.

31 POCOCK, J. G. A. Virtudes, direitos e maneiras, p.92. 
A lei natural, segundo Grotius, estava em estreito vínculo com a conservação dos direitos das pessoas, seja de propriedade ou de mérito. Os direitos passam a ocupar o lugar central da teoria da lei natural; a lei natural é de fato a obrigação sob a qual os homens estão para preservar a paz social, e a principal condição para a existência da paz na comunidade é o respeito dos direitos dos outros. Desta forma os homens são naturalmente livres para contratar e comerciar de todas as formas em relação a sua propriedade, e só a lei civil pode proibir certos tipos de contratos; a liberdade pessoal é parte da propriedade dos homens, suscetível também de contrato. É significativo que a expressão mais respeitável de uma teoria forte dos direitos jamais lida na Europa protestante pudesse conter tanto uma defesa da escravidão como uma defesa da resistência e da propriedade em comum in extremis; os pensadores da geração seguinte estarão profundamente divididos sobre qual das duas características da teoria dos direitos será mais importante. De Jure Belli ac Pacis (1625) continha de forma embrionária os elementos-chave da teoria política dos cinquenta anos seguintes, apesar de que os futuros desenvolvimentos seriam realizados em um mundo onde o princípio de sociabilidade, tão importante para o autor holandês, estariam sob forte ataque.

A teoria de Grotius proporcionou uma ideologia formidável aos campos rivais participantes do debate político inglês no século XVII. Podemos caracterizar os dois grupos como teóricos do direito conservadores e radicais; o primeiro grupo, dominado por John Selden e Thomas Hobbes, era cético em relação ao princípio de sociabilidade, aceitando, contudo, a escravidão e o absolutismo. O segundo grupo, por sua vez, resgatava o princípio de caridade interpretativa ${ }^{32}$ e esteve dominado pelos pensadores radicais ingleses de 1640. O conflito militar e ideológico na Inglaterra da primeira metade do século XVII será o cenário mais importante para o desenvolvimento desta teoria. ${ }^{33}$

A realização de Grotius foi notável, porém ela era incompleta em aspectos importantes. Em particular, a teoria de Grotius ressaltava a individualidade na área dos direitos, no entanto, enfatizava o elemento comunal na área da obrigação, e se bem era logicamente coerente também existia certa tensão entre ambas as perspectivas. Um dos aportes essenciais dos pensadores ingleses do século XVII foi complementar a teoria dos direitos naturais de Grotius com uma teoria ética e psicológica fortemente individualista.

32 Para Grotius, a princípio era possível renunciar a todos os direitos, mas a caridade (Charity) [Tuck chama esta ideia de princípio de caridade interpretativa] requeria que assumíssemos que não se renunciasse, de facto, a todos eles. Ver De Iure Belli, sobre a questão do princípio de resistência.

33 TUCK, Richard. Natural rights theories, p.80-1. Ver também TUCK, Richard. Grotius and Selden. 
O conflito entre o Parlamento e o Rei chegou a um ponto sem retorno no início de 1640; o conflito sobre o controle do exército precipitou a guerra civil e o colapso da ordem política inglesa. Inicialmente a disputa entre Rei e Parlamento foi realizada em termos tradicionais e legais. Foi só no processo da atividade e dos debates políticos nos anos imediatos a 1642 que os participantes começaram a entender a natureza diferente dos problemas enfrentados. As discussões se moveram da linguagem fundamental da lei e da constituição para a preocupação com a fonte última da obrigação política e legal. Do ponto de vista da história das ideias, as teorias do direito natural colocavam uma série de elementos fundamentais para o debate inglês, transformando muitas das questões em disputa. A teoria do contrato colocava uma doutrina geral da obrigação política, isto é, uma teoria sobre quando era possível ou não cumprir as promessas efetuadas. Uma teoria da obrigação in extremis levava em direção ao absolutismo, os contratos deviam ser mantidos inclusive ao custo da morte, porém também era possível sustentar uma posição diferente. A partir da teoria da obrigação política uma série de perguntas surgia: era possível atribuir direitos precisos ao Rei e aos súditos? Que ocorria quando um dos lados anulava o contrato? Existia um direito de resistência fundado na teoria da obrigação política? Quebrado o contrato onde residia a soberania política? Com a dissolução do governo estas perguntas surgiram com toda sua força e os grupos envolvidos tentaram justificar suas posições com base nas novas ideias que nasciam.

$\mathrm{Na}$ primeira parte dos anos de 1640 foram publicados na Inglaterra alguns dos trabalhos mais importantes da tradição conservadora dos direitos naturais, assim como também obras que constituíam uma tradição radical de falar de direitos naturais. Como afirma Tuck, a elaboração teórica de Grotius permitia prover a linguagem básica para as duas tradições: os conservadores recuperavam a ideia central de que os homens livres eram capazes de renunciar às suas liberdades, ao mesmo tempo em que os radicais recuperavam o princípio da caridade interpretativa (interpretative charity) aplicado para acordos políticos fundamentais. Este princípio implicava direitos inalienáveis: logicamente, os homens livres eram capazes no estado de natureza de renunciar a todos os direitos para sobreviver ou para se liberar, porém a caridade (charity) requeria que assumíssemos que eles não tinham de fazer isso. Nossos ancestrais, sendo racionais, não deveriam querer nos deixar completamente desprovidos de nossos direitos por terem eles perdido os seus. Grotius tinha invocado o princípio da caridade interpretativa para defender a resistência política e reivindicações de posse comum de propriedade em casos extremos para preservar a vida humana, e este era o argumento que apareceria, ano após ano, nas posições políticas dos pensadores radicais ingleses. Não exis- 
tia razão para supor que todos os que usassem esse argumento tinham lido Grotius: a caridade interpretativa era um princípio usado com o objetivo de modificar uma teoria forte dos direitos naturais, e no momento em que a linguagem dos direitos naturais se tornou suficientemente comum podia ser desenvolvida independentemente de Grotius. ${ }^{34}$

Um exemplo de argumentação baseada nas teorias do direito natural, em uma perspectiva não conservadora, é o texto de Henry Parker Observation upon Some of His Majesties Late Answers and Expresses (julho de 1642), um dos panfletos mais influentes do período. Parker, com o objetivo de refutar as reivindicações de poder absoluto feitas pelos partidários do Rei, utilizou uma combinação do princípio de caridade interpretativa e da ideia tradicional de obrigação (duty) natural de autodefesa para argumentar que as pessoas sempre deviam reservar direitos para si em qualquer acordo com seu soberano. ${ }^{35}$

Para explicar a relação existente entre soberano e povo, Parker utiliza um conceito chave no pensamento político do período, e que será retomado pelos Levellers, a noção de trust:

Eu considero que agora está suficientemente claro, que todo governo é apenas fiduciário, e que este e aquele Príncipe é mais ou menos absoluto, e ele é mais ou menos fidedigno e que todas as relações de confiança não são diferentes por natureza ou intenções, mas só em grau e extensão: e, portanto, sendo antinatural para qualquer Nação abrir mão de sua própria propriedade em se mesma absoluta, e para a mais suprema de todas as Leis, não podemos pensar que se possa sustentar com a intenção de qualquer confiança, que a defesa necessária deve ser prescrita e a preservação natural negada a qualquer pessoa. ${ }^{36}$

Para Parker o bem-estar das pessoas devia ser o fim último, o qual nunca podia ser confiado ao arbítrio do monarca, e este fim era mais importante que qualquer meio. Em Observations, Parker usa a noção de direito inalienável exclusivamente no contexto de defesa dos direitos da comunidade como um todo contra seu governante. Mas quando seus oponentes monarquistas o confrontam sobre este ponto argumentando que indivíduos pré-sociais devem

34 TUCK, Richard. Natural rights theories, p.142-143.

35 PARKER, Henry. Observation upon some of his majesties late answers and expresses. London: William Sheares, 1642.

36 "I conceive it is now sufficiently cleared, that all rule is but fiduciarie, and that this and that Prince is more and lesse absolute, and he is more or lesse trusted, and that all trusts differ not in nature or intent, but in degree only and extent: and therefore since it is unnuturall for any Nation to give away its owne propietie in it selfe absolutely, and to the supreme of all Lawes, we must not think that it can stand with the intention of any trust, that necessarie defence should be barred, and naturall preservation denied to any people". In: PARKER, Henry. Observation upon some of his majesties late answers and expresses. 
renunciar a todos seus direitos, Parker foi forçado a considerar a possibilidade de direitos individuais inalienáveis. Em um texto posterior, Jus populi (outubro de 1644), defendendo-se de seus críticos, Parker repudia explicitamente a teoria de Grotius de autocracia voluntária e nega a possibilidade de indivíduos racionais se transformarem em escravos. 0 argumento de Parker vai em direção a aceitar uma teoria dos direitos individuais inalienáveis, inclusive no próprio Jus populi, mas ao mesmo tempo está determinado a explicar os males da escravidão como resultado, em parte, de uma violação dos direitos sociais. ${ }^{37}$

Esta ambiguidade é interessante e mostra que existem diversas possibilidades de articulação entre conceitos como direitos inalienáveis, obrigação política, resistência e liberdade entre outros, a partir do uso da linguagem dos direitos naturais. E, ao mesmo tempo, expõe a desconfiança em relação às consequências políticas de uma linguagem política nova e com implicações não totalmente claras, como mostraram as discussões ao longo da guerra civil.

Pensadores conservadores também fizeram uso da teoria do direito natural para criticar as posições políticas do Parlamento e justificar as pretensões absolutistas do Rei. Um grupo importante destes pensadores, membros do chamado Tew Circle, modificaram aspectos da teoria do direito natural, no entanto, seguindo as linhas básicas da doutrina exposta por Grotius, Selden e Hobbes. Um dos textos mais expressivos foi Answer to a printed book (1642), atribuído a Falkand, Dudley Digges e William Chillingworth, este era principalmente uma crítica ao trabalho de Parker, Observations. A crítica envolvia uma refutação do argumento central de Parker de que sob a lei natural o homem tinha o dever de se proteger contra um ataque, e desta forma a ação militar contra as forças do Rei estava justificada. ${ }^{38}$

Dudley Digges, em The Unlawfulnesse of Subjects, Taking up Armes against their Soveraigne (1644), partia de uma distinção entre direito natural e lei natural. ${ }^{39} \mathrm{O}$ objetivo central, ao estabelecer esta distinção, era demonstrar que era possível renunciar a qualquer direito, incluído o direito natural

37 TUCK, Richard. Natural rights theories, p.146-147.

38 Outros escritos deste grupo argumentam em termos similares refutando esta reivindicação, como por exemplo: Of resisting the lawfull magistrate upon colour of religion (1642), e Humble address to the right honorable the Lord Fairfax and his Council of War (1649), de Henry Hammond.

39 "If we looke backe to the law of Nature, we shall find that the people would have had a clearer and most distinct notion of it, if common use of calling it Law had not helped to confound their understanding, when it ought to have been named the Right of nature; for Right and Law differ as much as Liberty and Bonds: Jus, or right not laying any obligation, but signifying, we may equally choose to doe or not to do without fault, whereas Lex or law determines us either to a particular performance by way of command, or a particular abstinence by a way of prohibition: and therefore jus naturae, all the right of nature, which now we can innocently make use of, is that freedome, not which any laws gives us, but which no law take away, and lawes are the severall restrains and limitations of native liberty", The Unlawfulnesse of Subjects, Taking up Armes against their Soveraigne (1644). 
de autodefesa. Desta forma, a obrigação do súdito era não resistir, ainda que o magistrado atuasse de forma coercitiva contra este. Esta elaboração oferecia uma resposta política para as condições de incerteza geradas pela guerra civil; os homens no estado de natureza eram livres de fazer contratos entre eles sobre qualquer assunto, e, uma vez feitos, a teoria geral da obrigação coagia a manter os mesmos. A autoridade política era resultado de um contrato que podia implicar a morte do contratante, porém era racional manter o compromisso estabelecido; desta forma o pensamento político conservador justificava a obediência ao poder real independentemente de suas conseqüências políticas. ${ }^{40}$

Parker estava, teórica e politicamente, comprometido com os líderes do exército e com o Parlamento, e sua autoridade tinha de ser salvaguardada, ao mesmo tempo em que a autoridade do Rei tinha que ser debilitada; e a maneira óbvia de fazê-lo era enfatizando os direitos da comunidade como um todo. Porém, a partir do processo de radicalização, resultado do processo de mobilização política, alguns pensadores começaram a usar a doutrina dos direitos inalienáveis contra o próprio Parlamento e contra os líderes do exército. Os Levellers retomaram a ideia de direitos individuais inalienáveis e insistiram que o Parlamento tinha usurpado esses direitos; a resposta frente a este desafio era que os direitos individuais deviam estar subordinados aos direitos sociais coletivos. ${ }^{41} \mathrm{Um}$ dos exemplos mais extraordinários de utilização da linguagem dos direitos pelos Levellers são os panfletos políticos de Richard Overton, em particular An Appeale From the Degenerate Representative Body (1647), no qual afirmava:

[A autoridade] sempre está ou nas mãos do Betrusted [os depositários da confiança] ou do Betrustees [quem deposita a confiança], enquanto o Betrusted e a execução de sua confiança [trust], ela permanece em suas mãos, no entanto quando o Betrusted trair e perder sua confiança, (como a dissolução das outras coisas) ela retorna de onde veio, ainda para as mãos dos Betrustees: Para todo o direito o poder humano é apenas do betrustes, conferido e transmitido por consentimento conjunto e comum, a cada indivíduo na natureza, é dada propriedade individual por natureza, a que não podem ser invadida ou usurpada por ninguém [...] para cada um em tanto ele próprio tem uma auto-propriedade, outra não poderia ser dele mesmo, e nesta não se pode presumir consequente, sem o consentimento; e, por nascimento natural, todos os homens são iguais e semelhantes para desfrutar de pro-

40 TUCK, Richard. Natural rights theories.

41 Sobre o pensamento político dos Levellers ver: WOOTTON, David. Leveller democracy and the Puritan Revolution. In: BURNS, J. H. (ed.). The Cambridge history of political thought 1450-1700. 
priedade e liberdade, cada homem por instinto natural visando sua própria segurança e bem estar. ${ }^{42}$

Neste texto, Overton coloca no centro de sua teoria um direito inalienável particular, o direito de auto-preservação, derivando este direito de um conjunto mais amplo ao qual nenhum ser racional pode renunciar. 0 argumento de Overton afirma que qualquer coisa que seja razoável desejar pode se constituir em um direito inalienável, estando sua recuperação inteiramente justificada; e ao mesmo tempo, sustenta a impossibilidade de que um homem racional renuncie a seus direitos. Neste ponto é possível ver que o princípio de caridade interpretativa foi ampliado de forma tal que chegou muito perto da noção do século XVIII de direitos inalienáveis da humanidade. ${ }^{43}$

A linguagem do direito civil e a linguagem do direito consuetudinário foram centrais como formas de argumentação política na luta por direitos e contra as prerrogativas reais. Ao mesmo tempo, o direito civil e o consuetudinário definiam os indivíduos do ponto de vista social e político como possuidores, outorgando direito e propriedade sobre as coisas e sobre si mesmos. No seu estudo sobre a teoria dos direitos naturais Richard Tuck problematizou a história do liberalismo, analisando como os direitos se tornaram a precondição, a ocasião e causa efetiva da soberania, de maneira que a soberania pareceu criatura dos direitos para cuja proteção existia. Este sem dúvida foi o principal tema do pensamento político moderno na sua etapa inicial. No entanto, o liberalismo por definir o indivíduo enquanto proprietário e detentor de direitos não o definiu enquanto cidadão com características políticas para assegurar sua participação na comunidade. Como consequência é necessário considerar, além da linguagem de lei e dos direitos, que é a história do liberalismo, outras linguagens que, no início da modernidade, foram centrais para o desenvolvimento da consciência cívica. ${ }^{44}$

42 "[authority] alwayes is either in the hands of the Betrusted or of the Betrustees, while the Betrusted and discharges of their trust, it remaineth in their hands, but no sooner the Betrusted betray and forfeit their Trust, but (as all things else dissolution) it returneth from whence it came, even to the hands of the Trustees: For all iust humaine power are but betrustes, confer'd and conveyed by iont and common consent, for the every individual in nature, is given individuall propriety by nature, not be invaded or usurped by any [...] for every one as he is himself hath a self propriety, else could not be himselfe, and on this no second may presume without consent; and by natural birth, all men are equall and alike borne to like propriety and freedome, every man by naturall instinct aiming at his owne safety and weale". In: WOLFE, Don M. Levellers manifestoes of the Puritan Revolution. New York: Thomas Nelson and Sons, 1944, p.162.

43 TUCK, Richard. Natural rights theories, p.149-150.

44 POCOCK, J. G. A. Virtudes, direitos e maneiras, p.92. 


\section{A perspectiva humanista}

A linguagem da lei partia de uma visão da política fundada na concepção do individuo como ser privado, perseguindo objetivos e salvaguardando suas liberdades; e, o que é fundamental, concebendo o governo como um mecanismo de preservação e proteção de sua liberdade individual. Um dos elementos centrais é que por ter definido o indivíduo como proprietário e possuidor de direitos, a linguagem da lei não o definiu como possuidor de uma personalidade adequada à participação no autogoverno..$^{45}$ Desta forma, é possível pensar em uma dialética entre a linguagem do direito e a linguagem da virtude. Se elas partem de pressupostos diferentes em relação ao fim da atividade política e ao dever do cidadão para com a comunidade, elas também tendem a complementar as insuficiências uma da outra. Então, podemos observar, no início da modernidade, a existência de duas histórias do discurso político que correm paralelas, preenchendo os vazios e complementando as carências para conseguir dar conta das novas formas que a política adquire. É possível, portanto, pensar na existência de uma relação complexa e contraditória entre pensamento liberal, como discurso da lei, e pensamento republicano, enquanto discurso da virtude.

A linguagem da virtude, construída a partir de conceitos como república, cidadão e virtude, precisou se transformar conceitualmente para se tornar operativo em um ambiente intelectual dominado por conceitos jurídicos, monárquicos e de obediência. O humanismo cívico, como desenvolvido no centro-norte da Itália nos séculos XV e XVI, tinha como pressuposto a existência de uma forma política caracterizada pela participação ativa dos cidadãos nos problemas políticos da comunidade. E os conceitos desenvolvidos pelo pensamento humanista, virtude, fortuna, corrupção, governo equilibrado, entre outros, buscavam dar conta de uma situação na qual a República, uma comunidade política universal, devia enfrentar os problemas próprios de uma existência particular, isto é, buscava resolver as tensões entre a tentativa de realização dos valores universais em uma forma histórica particular e finita. ${ }^{46}$ A Inglaterra do século XVII era um corpo político caracterizado pela experiência, capaz de engendrar um conjunto de costumes transmitidos de geração em geração, e não um corpo político de cidadãos buscando participar das decisões políticas da República. Portanto, foi necessária uma adaptação dos conceitos centrais do humanismo cívico às condições políticas e sociais da

45 POCOCK, J. G. A. Virtudes, direitos e maneiras, p.92 e 112.

46 Sobre o humanismo cívico e o pensamento político florentino ver, entre outras, as já clássicas obras de BARON, Hans. The crisis of the early Italian Renaissance. Princeton: University Press, 1966; SKINNER, Quentin. Los fundamentos del pensamiento politico moderno; e POCOCK, J. G. A. The maquiavellian moment. 
Inglaterra Stuart para que o discurso do republicanismo pudesse ser operativo nas condições de uma monarquia jurisdicional. Um dos elementos centrais deste processo de adaptação do humanismo inglês foi a reconfiguração do conceito de cidadão, projetando a imagem do humanista como conselheiro do príncipe; mediante este processo de apropriação e re-elaboração o humanismo contribuiu para o desenvolvimento de elementos chave para o surgimento da consciência cívica.

The Articulate Citizen and the English Renaissance de Arthur B. Ferguson é um livro fundamental relevância para entender o humanismo inglês. Neste texto Ferguson mostra o papel do humanismo a partir do período Tudor, especialmente a importância do conselheiro para o surgimento da noção de cidadão. Os pensadores humanistas deste período, nas suas análises das causas dos problemas do reino, adotaram visões renovadas em relação aos problemas do governo e da cidadania; ao tempo em que preparavam o caminho para uma era moderna de discussão política, antecipando muitas das atitudes características dos modernos cidadãos para com a sociedade em que viviam.

Para Ferguson o problema do conselho, visto da perspectiva dos cidadãos dos séculos XIV e XV, era essencialmente de censura e de crítica honesta e, desta forma era um problema essencialmente moral. Se o rei recebesse bons conselhos e se os Lordes (que eram seus conselheiros naturais) fossem suficientemente virtuosos para ouvir e atuar em consequência, os problemas poderiam ser resolvidos. O Parlamento e o próprio conselho do rei proviam os canais institucionais por meio dos quais os reclamos populares deviam chegar ao governo. Os cidadãos letrados colocavam para eles mesmos o dever de prover as fontes formais desses conselhos; este era um dever auto-imposto, um dever de consciência. Pregadores e poetas, clérigos e homens leigos sentiam-se na obrigação de servir como a voz das pessoas, que era também a voz de Deus, tornando-se, assim, porta-vozes da consciência pública. ${ }^{47}$

No período Tudor, o pensamento humanista tinha se difundido amplamente entre os intelectuais ingleses e suas lições tinham sido aplicadas aos problemas do reino. Dentro desse contexto de humanismo aplicado, emergiu na Inglaterra, afirma Ferguson, um novo ideal de cidadania inteligente e articulada. Como os humanistas cívicos da Itália, os conselheiros-cidadãos da Inglaterra Tudor extraíram do exemplo secular e racional da antiguidade clássica as lições que deviam aplicar para o beneficio da comunidade. Nesta nova visão, o conselho era mais do que uma crítica negativa; os humanistas acreditavam, baseados numa fé otimista, na possibilidade de educar os homens nos deveres do cidadão ativo e na eficácia da razão como meio de alcançar o bom gover-

47 FERGUSON, Arthur B. The articulate citizen and the English Renaissance. Durham: Duke University Press, 1965. 
no. Seus conhecimentos teriam pouco significado a não ser que pudessem ser aplicados em benefício da comunidade.

A estrutura institucional inglesa não era uma república no sentido clássico do termo, continuava a ser um tipo de associação política na qual o príncipe era a cabeça e onde a hierarquia de graus continuava sendo a marca característica do reino. Seria ainda necessário um esforço de adaptação conceitual dos elementos básicos do humanismo cívico para poder ver a Inglaterra como uma República clássica, e outro elemento-chave neste processo de adaptação foi a busca de um equivalente do cidadão republicano.

As análises de Ferguson sobre o humanismo inglês levam à consideração do papel do Parlamento e da legislação no desenvolvimento da consciência cívica. A Inglaterra do século XVII era uma estrutura política relativamente complexa, com seus tribunais da common law, sua administração local e a instituição central do Parlamento.

Esta estrutura institucional do país servia como um mecanismo de consulta nacional, e no lugar do magistrado que cumpria um papel subordinado era possível encontrar a figura mais complexa e cívica do conselheiro, que podia aparecer como um gentleman, representante de seu condado no Parlamento para aconselhar o príncipe sobre os diferentes assuntos do reino. Durante o século XVI, a gentry começou a assumir a representação de seus distritos e como consequência procurou um tipo de formação nas universidades e nos colégios de advogados que lhe permitisse cumprir seu crescente papel político no reino e na jurisdição conjunta com o rei. Esta educação tinha fundamentalmente um caráter humanista e foi essencial para que este grupo social, dinâmico do ponto de vista econômico e ativo do ponto de visto político, buscasse uma variante inglesa de um humanismo politicamente ativo e, deste modo, a formação humanista contribuiu para a ampliação de uma consciência cívica acessível aos ingleses. A partir do momento em que se produz um processo de ampliação da experiência política para os vários estados do reino foi admissível introduzir elementos do pensamento cívico no paradigma dominante da monarquia. ${ }^{48}$

De acordo com Pocock, é possível ver uma expansão das áreas de atuação das câmaras do Parlamento como resultado de uma mudança no esquema conceitual de percepção do mundo político. No momento em que a autoridade política do rei se encontrou com a capacidade cívica dos estados, foi possível aceitar a contribuição política dos súditos do reino, tanto na forma de atividade como na forma de conhecimento. As câmaras do Parlamento - a câmara baixa que representava os comuns e a câmara alta que representava a nobreza - começaram cada vez mais a tomar a iniciativa em vários assuntos do

48 POCOCK, J. G. A. The maquiavellian moment, p.353. 
reino; e a existência da tradição do humanismo inglês incorporou uma linguagem republicana que fazia possível que essas instituições fossem classificadas de maneira adequada como instancias dos "poucos" e dos "muitos"; como consequência foi aceitável pela primeira vez afirmar que o governo inglês sintetizava as melhores virtudes das formas puras de governo, monarquia, aristocracia e democracia.

Outro elemento importante para o republicanismo inglês, e que seria determinante na discussão política do século seguinte, foi o deslocamento da consciência cívica da Corte (Court) para o País (Country). Ao mesmo tempo em que os nobres e cavaleiros intensificavam o sentido de comunidade construído em torno da instituição do Parlamento e também em seus territórios, a própria Inglaterra começou a ser considerada em termos de uma comunidade política (commonwealth), na qual as relações entre estados e soberano eram dinâmicas. Este maior dinamismo nas relações fazia possível o emprego de um vocabulário de tipo maquiaveliano, em termos de fortuna, para expressar a instabilidade política; entretanto este novo vocabulário político, que lentamente construía uma visão republicana da política, ainda tinha que enfrentar a persistência de velhos modos de expressão centrados na autoridade descendente de Deus e no papel da hierarquia na ordem dominante. ${ }^{49}$

Uma teoria como a do governo misto ou balanceado era incompatível com as noções de autoridade descendentes prevalecentes no período Tudor. Os elementos da teoria republicana se adaptavam melhor a situações nas quais existiam problemas de legitimidade. Se a autoridade política continuava essencialmente em poder do Rei, a necessidade de consultar os estados do reino, nobres e comuns, permanecia simplesmente como prudencial e a linguagem do governo misto não era a mais apropriada para apreender as condições políticas. No entanto, quando o paradigma da monarquia colapsou e o Rei foi forçado a admitir, bem por força ou por direito, que ele compartilhava sua autoridade com outros, foi possível (do ponto de vista conceitual) caracterizar ao governo da Inglaterra como uma relação equilibrada entre Rei, Lordes e Comuns.

Desta forma, as primeiras décadas do século XVII parecem ter sido um ambiente propício para o surgimento de uma literatura política de clara inspiração republicana, e particularmente maquiaveliana. Um exemplo desta literatura é The prince or the maxims of State atribuído a Walter Ralegh. ${ }^{50}$ Apesar de citar Maquiavel de forma crítica, é possível observar neste texto a influência do pensador florentino no sentido de ser uma obra sobre a razão de

49 Sobre o desenvolvimento das ideologias Court e Country na Inglaterra de fins do século XVII e começo do XVIII, ver POCOCK, J. G. A. The maquiavellian moment, capítulo XII.

50 Sobre as controvérsias em relação a autoria da obra, ver POCOCK, J. G. A. The maquiavellian moment, p.355. 
estado, na qual a astúcia é aplicada para a preservação de formas de governo tanto legítimas como ilegítimas. Discutindo sobre os reinos novos adquiridos pela força, o texto afirma:

Primeiro, se eles eram súbditos antes de seu predecessor, ou tinham a mesma língua, formas, ou maneiras que em seu próprio país, é uma tarefa fácil manter esses países na obediência, no caso que a sangue do príncipe do referido país tenha sido totalmente extinta [...] No caso da invasão de um país estrangeiro, no qual o príncipe não tem nenhum direito ou cujo herdeiro legítimo ainda vive, não é próprio de um príncipe civil, e muito menos de um príncipe cristão, impor seu domínio a esse país; e, portanto, as práticas Maquiavélicas neste caso, para que funcionem de forma convincente devem extinguir o sangue real, são uma impertinência. ${ }^{51}$

Outro elemento relevante é a análise na distribuição apropriada das armas para as distintas formas de governo, monarquia, aristocracia e democracia, igualmente uma característica da tradição florentina. ${ }^{52}$

A obra The prerogative of Parliament, esta sim reconhecidamente atribuída a Ralegh, é outro exemplo da presença desta tradição. Este diálogo, entre um conselheiro de estado e um juiz de paz, ambos a serviço da Câmara dos Comuns, foi um dos primeiros exemplos de uma análise social, feita em termos maquiavelianos, das conflituosas relações entre os reis da dinastia Stuart e os parlamentos do período. 0 conselheiro sustentava que a prudência, e não a justiça, impunha ao rei consultar as vontades de seus parlamentos, como forma de mantê-los dominados; desta forma a autoridade real por sua natureza era tal que não podia ser exercida exceto por meios adequados à arte da política. 0 rei governava por artifícios, em um mundo de instabilidade e não perfeitamente conhecido; neste contexto, Ralegh afirmava que parte dos problemas do Rei em relação aos parlamentos residia na decadência do poder militar privado, anteriormente pertencente aos grandes nobres. ${ }^{53}$ Afirma o texto:

51 "First, if they have been subjects before to his ancestor, or have the same tongue, manners, or fashions as have his own country, it is an easy matter to retain such countries within obedience, in case the prince's of the said country be wholly extinct [...] As for the invasion of a foreign country, whereunto the prince hath no right, or whereof the right heir is living, it is not the part of a just civil prince, much less a Christian prince, to enforce such a country; and therefore the Machiavelian practices in this case, to make sure work by extinguishing the blood royal, is lewd an impertinent"; RALEGH, Sir Walter. The prerogatives of Parliaments. In: OLDYS, William e BIRCH, Thomas. (eds.). The works of sir Walter Ralegh, Kt., v.VIII. Oxford: University Press, 1829, p.18.

52 "Preserving of an oligarchy by sophisms. Rules (...) 4. In warlike exercises and arms: that the poor be not forced to have armour, horses, \&c. under pretence of sparing their cost, nor to be drawn from their trades by martial exercises; but to compel the richer sort to keep their proportion of armours, horse, \&c. by exercise fines, and to exercise themselves in warlike matters, \&c.” RALEGH, Sir Walter. The prerogatives of Parliaments, p.27.

53 POCOCK, J. G. A. The maquiavellian moment, p.356-357. 
[Juiz de paz]: (...) Os Senhores nos tempos antigos eram mais fortes, mais bélicos, melhor acompanhados, vivendo em seus domínios, do que são agora. Vossa senhoria deve ter presente em sua análise que existiam muitos condes que podiam pôr em campo mil cavalos berberes, muitos barões quinhentos ou seiscentos cavalos berberes, no entanto agora muito poucos deles podem fornecer vinte vigorosos para servir o Rei. Mas para dizer a verdade, meu senhor, os juízes de paz na Inglaterra têm combatido as injustiças da guerra na Inglaterra; o mandato do Rei tem preeminência sobre tudo, e o grande selo da Inglaterra, com aquele dos próximos condestáveis, servirá para contestar a ofensa dos grandes senhores em Inglaterra que queiram se voltar contra o Rei. A força, consequentemente, nestes últimos tempos, não deve ser menos satisfeita que os pares; assim como os últimos estão se tornando menos importantes, em virtude da preparação ao longo da Inglaterra, os comuns têm todas as armas em suas mãos. ${ }^{54}$

Vemos no argumento uma análise das causas secundarias própria da tradição florentina, na qual armas e soldados são centrais para a autoridade pública. Como afirma Pocock, este tipo de análise mostrava a consciência que os pensadores políticos do período tinham em relação às mudanças políticas e sociais que estavam em marcha. A Guerra das Duas Rosas entre as Casas Lancaster e York havia sido lutada por exércitos de vassalos que seguiam seus senhores, porém o fim da guerra marcou o enfraquecimento do poder da nobreza, e fundamentalmente o enfraquecimento de seu poder militar. No entanto, Ralegh, de forma similar a outros pensadores, estava utilizando a proposição de que os senhores tinham perdido seu poder militar anterior, com o objetivo de desenvolver a hipótese geral de que havia ocorrido uma mudança nas relações políticas e sociais entre rei, nobreza e povo. Desta forma é possível extrair duas conclusões importantes sobre o texto, por um lado, The prerogative of Parliament forma parte da crescente consciência histórica sobre a existência de um passado feudal da Inglaterra. Por outro, é significativo que esta consciência histórica se expressara em uma linguagem republicana; é a tradição de pensamento florentina sobre a relação entre a distribuição de armas como indicador

54 "[Justice of Peace]: (...) The Lords in former times were far stronger, more warlike, better followed, living in their countries, than now they are. Your lordship may remember in your reading, that there were many earls could bring into the field a thousand barbed horses, many baron five or six hundred barbed horses, whereas now very few of them can furnish twenty fit to serve the king. But to say the truth, my lord, the justices of peace in England have opposed the injustices of war in England; the king's writ runs over all, and the great seal of England, with that of the next constables, will serve the turn affront the greatest lords in England, that shall move against the king. The force therefore, in these latter ages, are no less to be pleased than the peers; for as the latter are become less, so by reason of the training through England, the common have all the weapons in their hand". RALEGH, Sir Walter. The prerogatives of Parliaments, p.183. 
da distribuição da capacidade política que outorgava o vocabulário apropriado para o crescimento de ideias sobre a importância do passado na explicação das mudanças políticas inglesas. ${ }^{55}$

Outro autor importante da tradição republicana do período foi Francis Bacon. A formulação baconiana, ainda que original, foi influenciada pelas obras de Maquiavel e Giordano Bruno. Em History of the Reign of King Henry VII, Bacon analisava dois temas característicos do pensamento maquiaveliano. Por um lado, da mesma forma que Ralegh, avaliava as transformações políticas da Inglaterra decorrentes das alterações na distribuição do poder militar entre os estados. Por outro, refletia sobre o papel central da infantaria como núcleo do exército, de forma a assegurar a expansão e a grandeza do estado. Nesta obra Bacon contrastava o vigor do campesino inglês, contrapondo-o com seu similar francês, e sugerindo que a dificuldade em impor taxações e governo sem consenso eram consequências da força do primeiro. ${ }^{56}$

O colapso da autoridade, o fim da monarquia e a guerra civil, foram os fatos chaves para fosse possível a incorporação sistemática de elementos republicanos no pensamento político inglês. Durante o período em que o esquema conceitual de jurisdictio e gubernaculum - autoridade descendente e costume ascendente - continuava funcionando, o rei tinha a obrigação de respeitar os direitos e os privilégios dos súditos, porém, isto acontecia em razão da prudência recomendada pelo costume e não como consequência da autoridade compartilhada entre soberano e súdito. Uma vez que se destruiu a relação entre autoridade e liberdade, como resultado da guerra civil, foi possível pensar conceitualmente em uma forma de comunidade política que fosse uma estrutura de participação no marco de um governo equilibrado, no estilo aristotélico ou polibiano, e foi possível avançar para uma reflexão teórica mais sofisticada. No entanto, sua aceitação se fez de forma reticente pelas mentes modeladas na common law e nos conceitos da monarquia, o que teve efeitos de grande importância no desenvolvimento do pensamento republicano, já que este não conseguiu se libertar totalmente de conceitos fundados na teologia, na casuística e em concepções milenaristas. Assim, é possível ver que o desenvolvimento de um pensamento republicano vigoroso se produziu no momento de derrota das propostas de reformas de cunho apocalípticas, de forma similar ao que acontecera com o pensamento do próprio Maquiavel no século anterior. ${ }^{57}$

55 POCOCK, J. G. A. The maquiavellian moment, p.356-357.

56 POCOCK, J. G. A. The maquiavellian moment, p.356-357.

57 POCOCK, J. G. A. The maquiavellian moment, p.357-360. 


\section{Conclusões}

Como afirmamos ao longo do texto, o pensamento político inglês do século XVII representou um momento fundamental na história do pensamento político, um momento basicamente de ruptura de determinadas concepções sobre o mundo político e de grande inovação no vocabulário relativo a ele. Um dos elementos centrais desta ruptura foi o surgimento da consciência cívica moderna, isto é, uma nova consciência sobre a dimensão pública da vida social. 0 desenvolvimento desta consciência cívica implicou no surgimento de conceitos originais que tentaram dar conta das novas relações entre autoridade e liberdade, e entre direitos e obrigações. Estes conceitos, no entanto, não surgiram a partir de uma tradição exclusivamente discursiva, mas se desenvolveram a partir das várias linguagens políticas disponíveis no período.

A linguagem da lei, que analisamos tanto na sua variante de lei civil como de lei natural, foi a principal linguagem a partir da qual se articulou a consciência cívica. A lei civil foi fundamental para a proteção da propriedade e da liberdade dos súditos e para limitar a prerrogativa régia; a estrutura social e fundamentalmente a propriedade existiam a partir de uma definição jurídica. A ideologia da common law cumpriu um papel essencial nas reivindicações do Parlamento e na afirmação da gentry na administração dos tribunais, funcionando desta maneira como uma forma de consciência cívica, já que definia o reino como uma estrutura pública e determinava uma forma de ação política. A linguagem da lei natural contribuiu de forma decisiva na construção desta concepção jurídica de liberdade. Integrando liberdade e direito, a liberdade era definida pela lei, concedendo direitos ao cidadão e também estabelecendo a moderna ideia de direitos individuais inalienáveis.

Se for verdade que a linguagem do direito foi um dos principais legados políticos do século XVII, as obras aqui examinadas sugerem também a importância da linguagem da virtude - do republicanismo cívico - e de uma articulação complexa e contraditória entre ambas no surgimento da moderna consciência cívica. ${ }^{58} \mathrm{~A}$ linguagem da lei tinha como pressuposto uma visão da política fundada na concepção do indivíduo como ser privado; e concebia o governo como um mecanismo de preservação e proteção da liberdade individual. Essa linguagem, porém, ao definir o indivíduo como proprietário e possuidor de direitos limitou a capacidade deste de partici-

58 Por sua vez a consolidação destas linguagens só foi possível depois do declínio do pensamento apocalíptico ocorrido com o fim do período revolucionário. 
par na comunidade política enquanto cidadão; foi necessário, portanto, o apelo aos conceitos provenientes da tradição republicana para - nas palavras de Pocock ${ }^{59}$ - definir o indivíduo como possuidor de uma personalidade adequada à participação no autogoverno. Assim, no início da modernidade, podemos observar a existência de uma relação complexa entre a linguagem da lei e a linguagem da virtude com o objetivo de dar conta de um novo tipo de relações políticas.

59 POCOCK, J. G. A. Virtudes, direitos e maneiras. 